Original Research Article

\title{
Evaluation of prescribing pattern of antidiabetic drugs in medicine outpatient clinic of a tertiary care teaching hospital
}

\author{
Vineet Kumar $^{1 *}$, Manmeet Topno², Manju Gari ${ }^{1}$, Megha Bansal ${ }^{1}$, Kishor Chakraborty ${ }^{1}$, \\ Shreya Lal ${ }^{1}$, Manisha Varshney ${ }^{1}$, Sumit Kumar Mahato ${ }^{1}$
}

\begin{abstract}
${ }^{1}$ Department of Pharmacology and Therapeutics, ${ }^{2}$ Department of Medicine, Rajendra Institute of Medical Sciences, Ranchi, Jharkhand, India

Received: 19 August 2017 Revised: 07 October 2017 Accepted: 27 October 2017

*Correspondence to: Dr. Vineet Kumar, Email: kumarvineetcmc@ gmail.com
\end{abstract}

Copyright: (c) the author(s), publisher and licensee Medip Academy. This is an openaccess article distributed under the terms of the Creative Commons Attribution NonCommercial License, which permits unrestricted noncommercial use, distribution, and reproduction in any medium, provided the original work is properly cited.

\begin{abstract}
Background: Diabetes is rapidly gaining the status of a potential epidemic in India with more than 62 million diabetics currently diagnosed with the disease. Drug utilization studies are of paramount importance for the optimization of drug therapy and promote rational drug use among health care providers. The aim of this study was to investigate the drug utilization pattern in type-2 diabetic patients. The objective of the study was to analyse the prescribing pattern of antidiabetic drugs in a tertiary care hospital.

Methods: A prospective, cross-sectional study was carried out in medicine outpatient clinic of tertiary care hospital, RIMS Ranchi for a period of 7 months. The data was analysed using WHO core indicators and Microsoft Excel 2013.

Results: The total number of encounters surveyed was 94. Avg no of drugs per prescription was 3.04. Percentage of drugs prescribed by generic name was found to be $34.2 \%$. Percentage of prescriptions was a) with antibiotics was $27.6 \%$, b) with insulin was $14.89 \%$, c) from essential drugs list $44.05 \%$. Most common co morbid disease was found to be hypertension present in $27.6 \%$ cases.

Most commonly use drug was found to be metformin followed by glimepiride.

Conclusions: Implementation of WHO core prescribing indicators by the prescribers would help us to reduce the cost, to recognize and prevent potentially dangerous drug-drug interaction and antibiotic resistance.
\end{abstract}

Keywords: Anti-diabetic drugs, Diabetes, Prescribing pattern, WHO core indicators

\section{INTRODUCTION}

The worldwide prevalence of Diabetes mellitus has risen dramatically over the past two decades. India had 69.2 million people living with diabetes $(8.7 \%)$ as per the 2015 data. Of these, it remained undiagnosed in more than 36 million people and that by 2030 this may rise well above half a billion cases. At present India is considered as the Diabetes capital of the World by WHO. World Health Organization (WHO) estimates that India will have 87 million cases of diabetes by $2030 .{ }^{1}$ A recent estimate suggested that diabetes was the fifth leading cause of death worldwide and was responsible for almost $6.8 \%$ of deaths worldwide..$^{2,3}$

Drug utilization has been defined by the WHO as the marketing, distribution, prescription, and use of drugs in a society with a special emphasis on the resulting medical, social, and economic consequences. ${ }^{4}$ Drug utilization studies are of paramount importance for the optimization of drug therapy and promoting rational drug use among health care providers. Irrational use of drugs is increasing expenditure and strain on health budgets. 
It has been estimated that $50 \%$ or more medicine expenditure is being wasted through irrational prescribing, dispensing and patient use of medicine. ${ }^{5}$

This study is therefore aimed at determining the pattern of drug use among type-2 diabetic patients and evaluate the degree of compliance among the physicians as to the current evidence and clinical guidelines and analyse the prescription according to WHO core drug prescribing indicators.

Aim of the study was to study the prescribing pattern of anti-diabetic drugs in a tertiary care hospital- RIMS Ranchi. Objectives of the study was to analyse the prescribing pattern of anti-diabetic drugs in a tertiary care hospital using WHO core drug prescribing indicators.

\section{METHODS}

It was prospective, cross-sectional study. The study was carried out at Medicine outpatient clinic of RIMS Ranchi. The duration of the study was from $1^{\text {st }}$ December 2016 to $30^{\text {th }}$ June 2017 (7 Months). The data was collected from the medicine OPD of RIMS Ranchi.

Patients with type 2 diabetes mellitus attending the OPD were randomly selected and their prescription analyzed.

\section{Inclusion criteria}

Prescriptions from all type-2 diabetic patients of:

- Either gender is included.

- Age more than 20 yrs.

\section{Exclusion criteria}

- Gestational diabetes mellitus

- Incomplete medical records.

- Age less than 20 yrs.

- Patients who got admitted were excluded from the study.

\section{Statistical analysis}

Data was analysed using WHO core drug prescribing indicators and Microsoft excel 2013.

\section{Formula adopted from the WHO's manual for prescribing}

Indicators assessment ${ }^{6}$

1. Average number of drugs per encounter= Total number of drugs prescribed/Total number of encounters sampled.

2. Percentage of drugs prescribed by generic name $=$ (Number of drugs prescribed by generic name/ Total number of drugs prescribed) x 100 .
3. Percentage of encounters with an antibiotic prescribed $=($ Number of patient encounters with an antibiotic/ Total number of encounters sampled) $\mathrm{x}$ 100.

4. Percentage of encounters with an injection prescribed $=($ Number of patient encounters with an injection prescribed/Total number of encounters sampled) x 100.

5. Percentage of drugs prescribed from essential drugs list $=$ (Number of drugs prescribed from essential drugs list/ Total number of prescribed drugs ) x 100 .

Table 1: Summary of results obtained at RIMS using WHO core indicators. $(n=94$ encounters $)$.

\begin{tabular}{|llll|}
\hline $\begin{array}{l}\text { Prescribing } \\
\text { indicators }\end{array}$ & $\begin{array}{l}\text { Total } \\
\text { drugs/ } \\
\text { encounters }\end{array}$ & $\begin{array}{l}\text { Average/ } \\
\text { percent }\end{array}$ & $\begin{array}{l}\text { Standard } \\
\text { or ideal }\end{array}$ \\
\hline $\begin{array}{l}\text { Average number } \\
\text { of drugs per } \\
\text { encounter }\end{array}$ & 286 & 3.04 & $1.6-1.8$ \\
\hline $\begin{array}{l}\text { Percentage of } \\
\text { Drugs prescribed } \\
\text { by generic name }\end{array}$ & 98 & $34.2 \%$ & $100 \%$ \\
\hline $\begin{array}{l}\text { Percentage of } \\
\text { drug encounter } \\
\text { with antibiotics }\end{array}$ & 26 & $27.6 \%$ & $20.0-$ \\
\hline $\begin{array}{l}\text { Percentage of } \\
\text { drug encounter } \\
\text { with injections }\end{array}$ & 14 & $14.89 \%$ & $13.4 \%$ \\
\hline $\begin{array}{l}\text { Percentage of } \\
\text { Drugs prescribed } \\
\text { from EDL }\end{array}$ & 126 & $44.05 \%$ & $100 \%$ \\
\hline
\end{tabular}

\section{RESULTS}

Total no of prescriptions audited, or encounters surveyed was 94 .

The total no of drugs in these were 286 and hence the average no of drugs per prescription came out to be 3.04.

Out of 94 prescriptions it was found that 46 were male and 48 females (Figure 1).

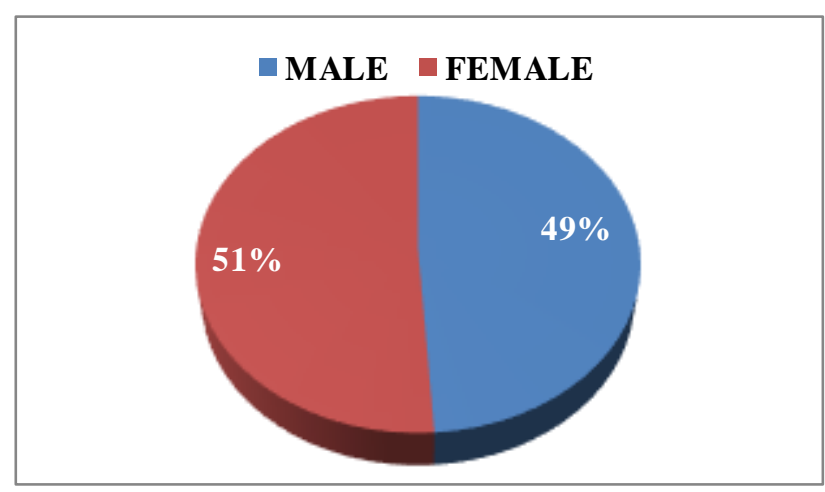

Figure 1: Gender wise distribution of observed encounters. 
Most patients belonged in the age group of 41-50 yrs (40) followed by 51-60 yrs (20) age group. 98 drugs or $34.2 \%$ drugs were prescribed using their generic names.

Among the drugs used for diabetes 24 patients received a single drug, 44 patients 2 drugs and 26 patients received 3 drugs (Figure 2).

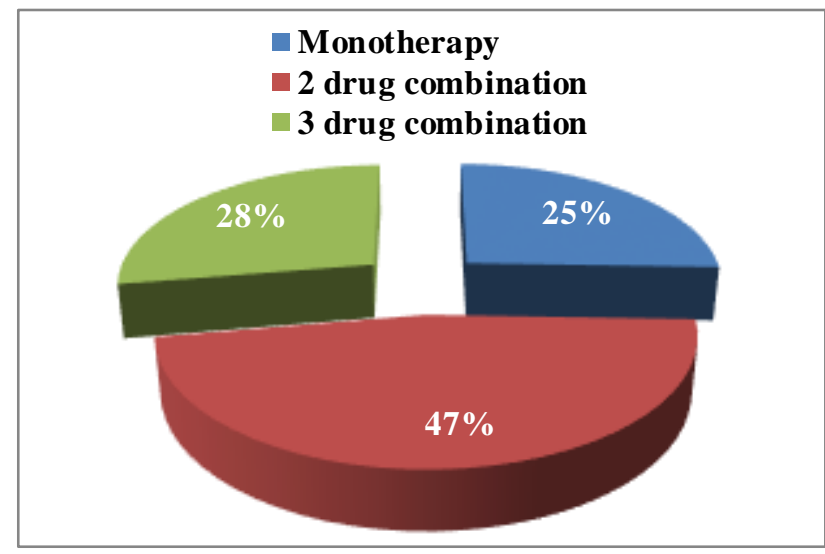

Figure 2: Monotherapy and combination therapy of antidiabetic drugs.

Among the anti-diabetic drugs, most common drug prescribed was Metformin present in 76 prescriptions $(80.85 \%)$ followed by glimepiride present in 48 prescriptions $(51.06 \%)$ (Table 2).

Table 2: Frequency of drugs used.

\begin{tabular}{|ll|}
\hline Drug therapy & Frequency \\
\hline Metformin & $76(80.8 \%)$ \\
\hline Glimepiride+Metformin & $48(51.06 \%)$ \\
\hline Teneligliptin & $8(8.51 \%)$ \\
\hline Voglibose & $6(6.38 \%)$ \\
\hline Insulin & $14(14.89 \%)$ \\
\hline
\end{tabular}

It is to be noted that glimepiride was never prescribed alone and was always given in combination with metformin. Monotherapy with metformin was done in 20 cases $(21.27 \%)$.

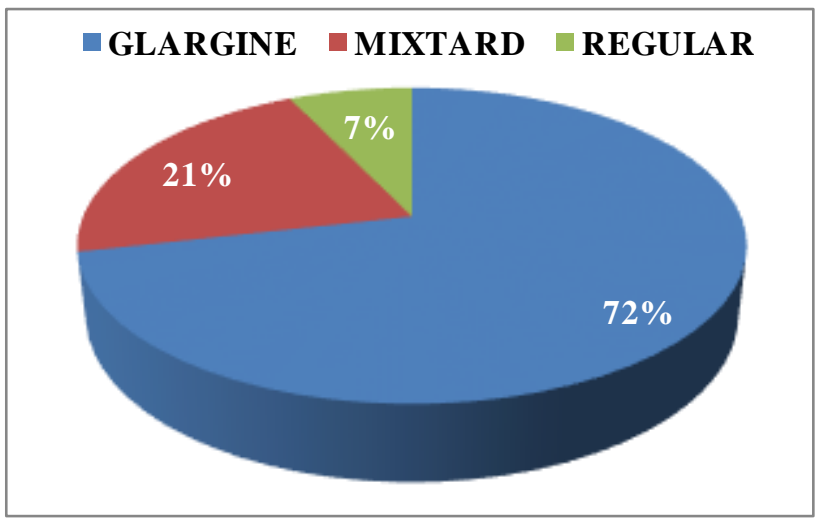

Figure 3: Types of insulin used.
Insulin was the only injectable drug given in all the prescriptions we analysed and was given in $14.89 \%$ of the patients, the most common being insulin glargine given in $10.63 \%$ patients while insulin mixtard given in $3.2 \%$ patients and regular insulin in $1.06 \%$ patients (Figure 3 ).

A total of 26 prescriptions contained antibiotics (27.6\%) and the most common was amoxicillin with clavulanic acid present in 12 prescriptions (12.76\%) (Figure 4).

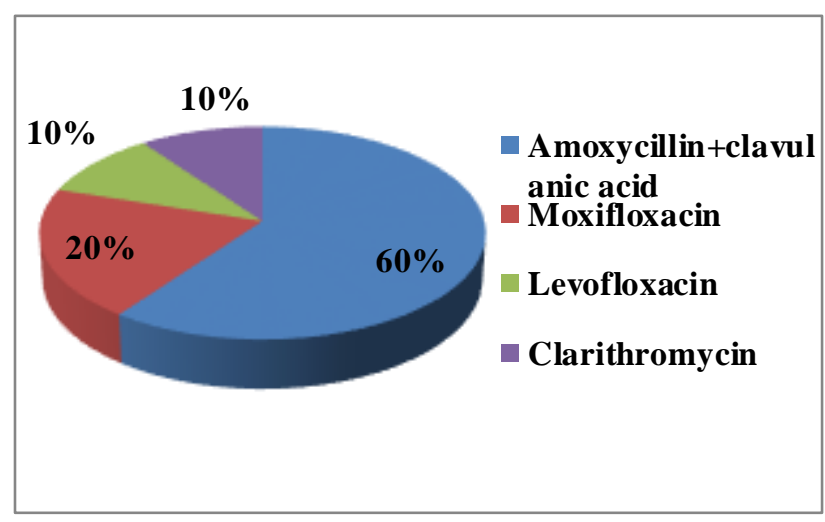

Figure 4: Antibiotic usage.

60 Patients had only diabetes while 34 had other comorbid conditions too (Figure 5).

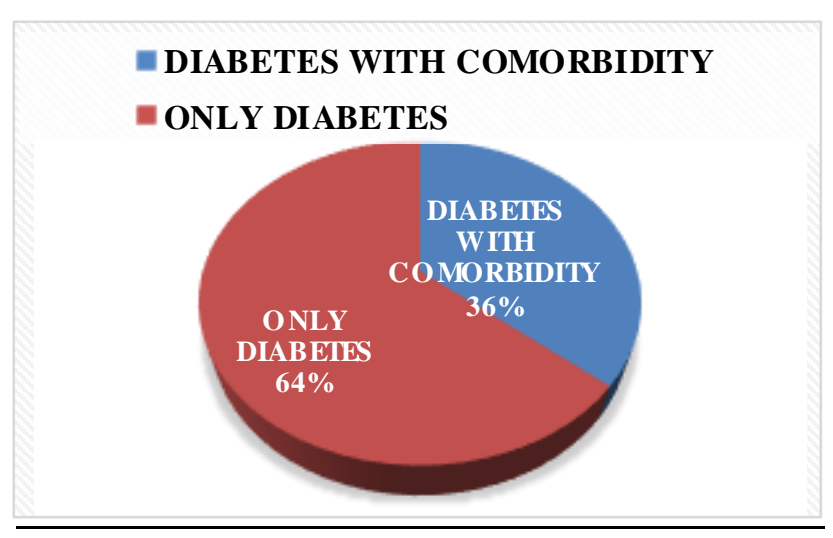

Figure 5: Percentage of diabetes with and without comorbidity.

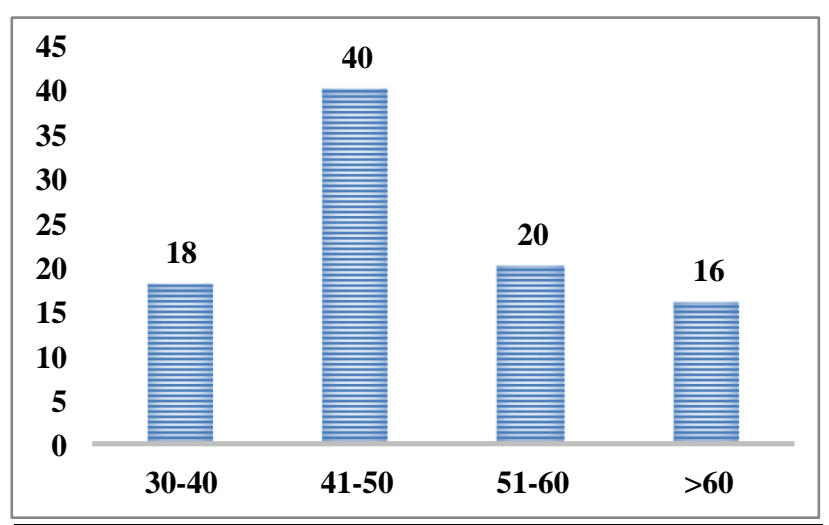

Figure 6: Age group distribution of patients. 
Other drugs prescribed were anti-hypertensives, antitubercular drugs, anti-malarials, antipyretics/analgesics and multivitamins depending on the diagnosis of the patient.

\section{DISCUSSION}

The worldwide prevalence of Diabetes mellitus has risen dramatically over the past two decades. Fortunately, in many patients complications of diabetes can be mitigated by sustained control of blood glucose level applying wide variety of treatment options. Hence Individuals with Type $2 \mathrm{DM}$ are considered on high priority as they are potential candidates for rapid evaluation to prevent and halt the progression of complications with proper medications.

In this study, we found a higher incidence of diabetes in elderly patients with a high incidence in age group of 4160 years $(63.8 \%)$ (Figure 6). This finding is in accordance with similar study conducted by Upadhyay et al. ${ }^{7}$

A high proportion of diabetic patients in this study were represented by females (51\%) similar to the study from UAE and in contrast with other studies from India. ${ }^{8-11}$

Infact slight preponderance of females was noticed similar to the study by Suthars on L et al. ${ }^{12}$ In contrast, some other studies indicated male predominance in their reports. ${ }^{13-16}$

In this study, hypertension $(76.47 \%)$ was the commonest co-morbidity observed. Different studies also reported similar observation with regard to the co-morbidity in patients with diabetes. . $^{8,11,16-18}$

The average number of drugs per prescription was 3.04 which is comparable to the study from UAE. ${ }^{8}$ Prescriptions with 5 and more than 5 drugs were found among patients above 50 years of age and with co-morbidities. There were no gender differences in the mean number of drugs prescribed. The most commonly co-prescribed medications along with antidiabetic drugs were antihypertensives.

Among the antidiabetic drugs metformin was the most commonly prescribed drug as monotherapy as well as in combination, which is similar to findings of and in contrast to where Sulfonylureas were found to be the most commonly prescribed antidiabetic drug. . $^{71,15,16,18-20}$

Among the sulfonylureas, glimepiride was the most commonly prescribed drug along with metformin which is similar to studies. ${ }^{10,18}$ Metformin is one of the safest and most cost effective drug compared to other drugs in terms of hypoglycaemia and decreasing BMI, hence this could be the most probable reason for this finding. Also this finding is in accordance with the clinical guidelines given by Canadian Diabetes Association, International Diabetes Federation, and National Institute of Health and Clinical Excellence. ${ }^{21-23}$
Teneligliptin was the only drug used from the DPP-4 inhibitors group and was given in $8.51 \%$ while voglibose was given in $6.38 \%$ patients.

A total of 26 prescriptions contained antibiotics $(27.6 \%)$ and the most common was amoxicillin with clavulanic acid present in 12 prescriptions $(12.76 \%)$.

Other antibiotics prescribed were clarithromycin, levofloxacin and moxifloxacin.

Most common complaint among the patients prescribed antibiotics was upper respiratory tract infection.

The percentage of drugs prescribed by generic names in the present study is $34.2 \%$, which is extremely low considering the standard derived to serve as ideal (100\%). This further emphasizes the need to reduce the cost of medications to patients through increased prescription of drugs in their generic names. In another study of 12 developing countries the percentage of generic drugs prescribed was $58 \%$ in Nigeria which is also below the standard. Our study also showed much lower percentage of prescriptions with generic name. The reason for this could be many; namely lucrative advertisements by the pharmaceutical companies, limited awareness about the prescribing guidelines of WHO by the prescribers, insufficient availability of generic drugs in our pharmacy (as per records most drugs are unavailable at all times). Prescribing generic drugs could decrease the economic burden on the patients. Further, educational intervention methods and strict compliance to WHO drug policies could play a role in generic prescribing.

Percentage of encounters in which antibiotics were prescribed in our tertiary care center was $27.6 \%$. This result is close to the standard $(20.0 \%-26.8 \%)$ derived to be ideal. This shows that antibiotics are being judiciously used in our hospital.

Limitations of the study include a relatively small sample size which might restrict the generalization of the findings. A study over a longer period of time with a bigger sample size would help us in further corroborating the findings and generalizing it.

\section{CONCLUSION}

In India, the steady migration of people from rural to urban areas and corresponding change in life-style are affecting the incidence and prevalence of diabetes. The prescribing pattern of antidiabetic drugs showed metformin to be the most commonly prescribed drug followed by glimepiride.

Appropriate use of antibiotics and injections per encounter suggests sensible use of the same.

Polypharmacy in our study indicates occurrence of diabetes with comorbid conditions which leads to high cost of treatment, more drug interactions and non-compliance. 
Lack of knowledge of the use of generic name and drugs listed under EDL requires awareness among the prescribers.

Implementation of WHO core prescribing indicators by the prescribers would help us to reduce the cost, to recognize and prevent potentially dangerous drug- drug interaction and antibiotic resistance.

\section{Funding: No funding sources}

Conflict of interest: None declared

Ethical approval: The study was approved by the Institutional Ethics Committee

\section{REFERENCES}

1. Shaw JE, Sicree RA, Zimmet PZ. Global estimates of the prevalence of diabetes for 2010 and 2030. Diabetes Res Clin Pract. 2010;87:4-14.

2. Powers AC. Diabetes mellitus: In. Harrison's principles of internal medicine. Fauci, Braunwald, Kasper, Hauser, Longo, Jameson et.al. The Mcgraw Hill Company. United States of America. $18^{\text {th }} \mathrm{Ed}$. 2012;386-394.

3. Wild S, Roglic G, Green A, Sicree R, King H. Global prevalence of diabetes: Estimates for the year 2000 and projections for 2030. Diabetes Care. 2004;27:1047-53.

4. Tognoni G, Liberati A, Pello L, Sasanclli E, Spagnoli A. Drug utilization studies and epidemiology. Rev Epifemiol. 1983;31:59-71.

5. Binu M, Sabbu R, Surendra K, Hiremath D. Assessment of Drug Prescribing Practices Using Who Prescribing Indicators In A Private Tertiary Care Teaching Hospital. IRJIPS. 2013;1:26-31.

6. World Health Organization. How to investigate drug use in Health Facilities: selected drug use indicators. WHO/DAP/93.1. Geneva, 1993.

7. Upadhyay DK, Palaian S, Ravi Shanker P, Mishra P, Sah AK. Prescribing pattern in diabetic outpatients in a tertiary care teaching hospital in Nepal. Journal of Clinical and Diagnostic Research. 2007;3:248-55.

8. Lisha JJ, Mohammed A, Jayadevan S, Jayakumary M, Das R, Jenny J, et al. Age and Gender-Based Utilization Pattern of Antidiabetic Drugs in Ajman, UAE. Mal J of Pha Sci. 2012;10(1):79-85.

9. Patel M, Patel IM, Patel YM, Rathi SK. A Hospitalbased Observational Study of Type 2 Diabetic Subjects from Gujarat, India. J Health Popul Nutr. 2011 Jun;29(3):265-72.

10. Sayed AHA, Churi S, Kumar RYS. Study of drug utilization pattern of antihyperglycemic agents in a South Indian tertiary care teaching hospital. Indian J Pharmacol. 2012 Mar-Apr;44(2):210-4.

11. Ramesh R, Kumar SV, Gopinath S, Gavaskar B, Gandhiji G. Diabetic knowledge of rural community and drug utilization pattern in a tertiary care hosptial.
International Journal of Pharmacy \& Life Sciences. 2011;2(1):531-5.

12. Sutharson L, Hariharan RS, Vamsadhara C. Drug Utilization Study in Diabetology Outpatient Setting of a Tertiary Hospital. Indian $J$ of Pharmacol. 2003;35:237-40.

13. Sudha V, Shukla P, Patidar P. Prescribing Pattern of Antidiabetic Drugs in Indore City Hospital Indian. J of Pha Sci. 2008;70(5):637-40.

14. Boccuzzi SJ, Wogen J, Fox J. Utilization of Oral Hypoglycemic Agents in a Drug-Insured U.S. Population. Diabetes Care. 2004;24(8):1411-5.

15. Johnson JA, Pohar SL, Secnik K. Utilization of diabetes medication and cost of testing supplies in Saskatchewan, 2001. BMC Health Serv Res. 2006;6:159.

16. Yurgin N, Secnik K, Lage MJ. Antidiabetic prescriptions and glycemic control in German patients with type 2 diabetes mellitus: a retros pective database study. Clin Ther. 2007;29(2):316-25.

17. AbdulGO. Jimoh, Sabir AA, Chika A, Sani Z. Pattern of Antidiabetic Drugs Use in a Diabetic Outpatient Clinic of a Tertiary Health Institution in Sokoto, North-western Nigeria. Journal of Medical Sciences. 2011;11:241-5.

18. Patel B, Oza B, Patel KP, Malhotra SD, Patel VJ. Pattern of antidiabetic drugs use in type-2 diabetic patients in a medicine outpatient clinic of a tertiary care teaching hospital. Int $\mathbf{J}$ of Basic \& Clinical Pha. 2013;2(4):485-91.

19. Chiang CW, Chiu HF, Chens CY. Trends in the use of oral antidiabetic drugs by outpatients in Taiwan: 1997-2003. J of Cli Pha and Ther. 2006;31:73-82.

20. Al Khaja KA, Sequeira RP, Mathur VS. Prescribing patterns and therapeutic implications for diabetic hypertension in Bahrain. Ann Pharmacother. 2001;35(11):1350-9.

21. CDA. Clinical practice guidelines for the prevention and management of diabetes in Canada. Canadian Diabetes Association, 2008. Available at: http://www.diabetes.ca/files/cpg2008/cpg-2008.pdf.

22. IDF. Clinical guidelines task force: Global guideline for type 2 diabetes. International Diabetes Federation, Brussels, 2005. Available at: http://www.idf.org/webdata/docs/IDF\%20GGT2D.pd f.

23. NIHCE. Type 2 diabetes: The management in primary and secondary care (update). National Institute for Health and Clinical Excellence; 2010.

Cite this article as: Kumar V, Topno M, Gari M, Bansal M, Chakraborty K, Lal S, et al. Evaluation of prescribing pattern of antidiabetic drugs in medicine outpatient clinic of a tertiary care teaching hospital. Int J Basic Clin Pharmacol 2017;6:2843-7. 